\title{
Assessments of Anxiety Levels and Working Conditions of Health Employees Working in COViD-19 Pandemic Hospitals
}

\author{
Sedat Bostan ${ }^{1}$, Mahmut Akbolat ${ }^{2^{\star}}$, Ahmet Kaya ${ }^{3}$, Musa Ozata ${ }^{4}$, Deniz Gunes ${ }^{1}$
}

${ }^{1}$ Ordu University, Faculty of Health Sciences, Department of Health Management, Ordu, TURKEY

${ }^{2}$ Sakarya University, Sakarya Business School, Department of Health Management, Sakarya, TURKEY

${ }^{3}$ Ordu University, Faculty of Medicine, Cardiology USA, Ordu, TURKEY

${ }^{4}$ Ahi Evran University, FEAS, Department of Health Management, Kirsehir, TURKEY

*Corresponding Author: makbolat@sakarya.edu.tr

Citation: Bostan S, Akbolat M, Kaya A, Ozata M, Gunes D. Assessments of Anxiety Levels and Working Conditions of Health Employees Working in COViD-19 Pandemic Hospitals. Electron J Gen Med. 2020;17(5):em246. https://doi.org/10.29333/ejgm/8228

\begin{tabular}{|c|c|}
\hline ARTICLE INFO & ABSTRACT \\
\hline Received: 20 Apr. 2020 & The study aims to identify health care workers' risk of COVID-19 and to determine employees' views on working \\
\hline Accepted: 27 Apr. 2020 & $\begin{array}{l}\text { Conditions and the fight against COVID-19 in general, and to present their concerns. The study utilized a survey } \\
\text { form developed by researchers as a data collection tool. The research was conducted on } 736 \text { health workers in the } \\
\text { Turkish population using the online survey method. Descriptive statistical methods, chi-square analysis, and } \\
\text { correlation analysis were used in the analysis of the data. The data was carried out in a } 95 \% \text { confidence range. } \\
\text { According to the study's findings, } 31.7 \% \text { of the health care workers involved in the study had contact with } 19 \text { cases } \\
\text { of COVID-19; } 27.3 \% \text { provided services to patients diagnosed with COVID-19. There is a relationship between the } \\
\text { professional groups of health care workers who have been contacted by COVID-19 cases and the professional } \\
\text { groups of those who provide services. Among the participants, only } 35 \text { people had a diagnostic test, } 15 \text { of which } \\
\text { were positive for COVID-19 results. Although health care workers find working conditions and authorities to be } \\
\text { moderate in tackling COVID-19, their anxiety levels are high. Although health care workers provide services to } \\
\text { COVID-19 diagnosed patients, they are not protected against the risk of infection by adequate testing. The risk of } \\
\text { transmission threatens more groups of nurses. Considering that COVID-19 is a global threat, measures should be } \\
\text { taken to protect health care workers and their families and professional support should be given to address their } \\
\text { concerns. }\end{array}$ \\
\hline
\end{tabular}

Keywords: COVID-19, health care workers, anxiety, Turkey

\section{INTRODUCTION}

COVID-19 came up on December 31, 2019, by Chinese health authorities reporting a cluster of cases of acute respiratory diseases in people associated with the Hunan seafood and animal market in Wuhan city, Hubei Province, Central China. On January 7, 2020, Chinese health authorities confirmed that a new coronavirus (2019-nCoV) was associated with this first cluster. It then began to spread rapidly in China and many other countries (1-3). COVID-19, which became a terrible problem all over the world, infected 972303 people and killed 75853 people (4).

The sudden and fast spreading of COVID-19 pandemic all over the world caused a sudden increase in the workload of health care workers in parallel with the possible increase in mortality rates and the spread of large numbers of people. Moreover, the fact that the extent of the problem is not fully understood can lead to both serious loss of morale motivation and mental health problems in health care workers (5]) This has been shown to reveal high rates of anxiety, insomnia and distress symptoms in health care workers (6). After this worldwide event, almost all medical specialties underwent a rapid overhaul of diagnostic and treatment algorithms in treatment approaches with the aim of both preventing the spread of the disease and protecting health care workers while treating the patient (7). Similarly, measures have been taken in Turkey. In this context, it is recommended to avoid moving patients from room or area to another area unless medically necessary, and to use portable X-ray devices and/or other important diagnostic devices designated for possible 2019$\mathrm{nCoV}$ patients. Since it is not possible to equip portable diagnostic devices and if the patients need to be removed, procedures for handling must be determined to minimize the professionals' contact with employees, other patients, and visitors, and it must be ensured that a face mask be worn in the transfer case and to be taken as the last case if possible (8).

The worldwide outbreak of COVID-19 has become a clinical threat to the general population and health care workers. However, information about this new virus remains limited (9). Besides, inadequate personal protection of health care workers, prolonged exposure to large numbers of infected patients (increased virus load), abnormal levels of workload and lack of personal protective equipment further increase the risk of infection for health care workers (10). Besides, health care workers who are in close contact with patients may be excluded, and people who send good messages from afar may exhibit discriminatory behavior even if necessary social 
distance and adequate measures are taken when they see them in shopping, in apartments and at home (11). Besides, the psychology of protection and prevention caused by the inability to estimate the size of the event can make the living conditions of health care workers even more difficult.

Estimating the high risk of being infected with COVID-19 virus in health care workers (12) are among the major factors affecting health care workers' medical habits and treatment priorities. It is also important to see the problems experienced by health care workers in the examples of China, Italy, and Spain. In particular, the problem of hospitals being filled quickly, the inability to find a place to sleep, the possibility of not finding enough teams and equipment led to a rapid change in general approaches. The appearance of a puzzler in the working environment in this way can cause tension and anxiety levels to develop in health care workers. Stress developing in the working environment is expected to create tension in the employee due to physical or psychological reasons (13). Also, the emergence of a much unknown situation is seen as a situation that increases the concern of health care workers to protect themselves and their relatives.

Against people perceived as threatening a person's emotional, mental and physical changes showed, anxiety which is defined as a state of unpleasant arousal (14) can be expressed as fear and tension that is felt in case of threat (15). The more threatening the individual perceives the event, the more intense the anxiety he or she experiences (16). Therefore, it becomes important to answer the question of how to control the anxiety levels of health care workers when working in an abnormal environment and how to affect this situation in working conditions and social conditions.

Global developments regarding the COVID-19 and safety of the area in which health care workers served have become a serious issue, both physically and emotionally. This study aimed to demonstrate how the working conditions of health care workers in the Turkish population and the struggle against COVID-19 were evaluated by health care workers and whether working in risky environments and abnormal conditions affected their anxiety levels.

\section{MATERIALS AND METHODS}

\section{Population and Sampling}

The population of the study consists of health care workers working in different health institutions in Turkey. In the study, an internet survey method was used to reach all regions and ensure employee participation. 736 health care workers participated in the study. 229 of the participants were physicians (31.1\%), 309 of them were nurses $(42.0 \%), 124$ of them were other health care workers $(16.8 \%)$ and 74 of them were administrative staff $(10.1 \%) .60 .5 \%$ of the participants were female and $39.5 \%$ were male professionals. $31.1 \%$ of the participants were $\geq 29,34.6 \%$ were $30-39,29.5 \%$ were $40-49$, and $4.9 \%$ were over the age of $\geq 50,29.3 \%$ were worked for $\geq 10$ years, $33.8 \%$ were $\geq 11-20$ years, and $21.6 \%$ were $\geq 21$ years.

\section{Data Collection Tool and Process}

As a data collection tool in the research of the participant's socio-demographic characteristics, COVID-19 contact and work in hospitals due to pandemic, their anxiety conditions, working conditions, and to put forward their views on the struggle for COVID-19, Attitude and Opinion Scale of the Health Care Workers Against COVID-19 Pandemic was used (Appendix$1)$.

In the process of developing the scale, in-depth interviews were conducted with health care workers and their views on working conditions, anxiety situations and the fight against the epidemic, in general, were determined. In the second phase, the statements that make up the scale were formed by the researchers. The draft scale was then sent to 10 academics working in the field and their opinions were taken. The pilot implementation of the scale was carried out after the revised statements were removed from the scale. In this process;

- For the reliability study, the substance-total score correlations were analyzed and the lower correlations were removed from the scale.

- Exploratory factor analysis was applied for the discovery of the hidden structures formed by substances.

- Cronbach Alpha coefficients were calculated for internal consistency analysis for reliability analysis of the lower dimensions.

Attitude and Opinion Scale of the Health Care Workers Against COVID-19 Pandemic consisting of three dimensions and 20 statements such as; working conditions as a result of pilot implementation (1-6th and 12-13th statements), anxiety (7-10th statements) and social struggle (14-20th statements), has been established.

Since face-to-face interviews were not possible due to the pandemic, the internet was used to collect data and health care workers were asked to fill out the questionnaire by clicking the link attached to the e-mails sent around the country. Data was provided from 760 health care workers as a result of the study. But it has been extracted from 24 survey datasets that are incomplete or found at extremes.

\section{Statistical Analysis}

To test the objectives of the study, SPSS 22 and Amos 22 statistical software were used. The analysis was carried out in a confidence range of $95 \%(p=0.05)$. Before the analysis of the data, it was examined normality test and it was understood that the data showed normal distribution. Descriptive statistical methods, Chi-square analysis, and correlation analysis were used in the study.

\section{Validity and Reliability Analysis of the Scale}

The validity and reliability analysis of the scale was conducted in three stages. Exploratory factor analysis was carried out in the first phase. Validity is the degree to which a test or scale measures what is intended to be measured (17). To measure the validity of the scales, first exploratory factor analysis and then confirmatory factor analysis were conducted. Table 1 shows the results of exploratory factor analysis and reliability analysis of the scale. As seen in the table,

The Kaiser-Meyer-Olkin (KMO) sample adequacy test result of the scale was 0.867 . As the KMO value approaches 1 , the sample size used in the study reaches perfection and 0.80 is considered to be very good and 0.90 perfect (18). Bartlett's Test of Sphericity result, which was used to evaluate the scale's suitability for factor analysis, was found to be significant $(p=0.000)$. Accordingly, the scale is suitable for factor analysis. The total variance described on the scale is $57.092 \%$. In the second phase, a validating factor analysis of the scale was 
Table 1. Validity and reliability analysis results of the scale

\begin{tabular}{|c|c|c|c|}
\hline \multicolumn{3}{|c|}{ Kaiser-Meyer-Olkin Measure of Sampling Adequacy. } & 0.867 \\
\hline \multirow{3}{*}{ Bartlett's Test of Sphericity } & \multicolumn{2}{|c|}{ Approx. Chi-Square } & 7788.584 \\
\hline & \multicolumn{2}{|c|}{ Df } & 190 \\
\hline & \multicolumn{2}{|c|}{ Sig. } & 0,000 \\
\hline Total variance & $\% 57.092$ & Cronbach Alpha & 0.837 \\
\hline Size / Expressions & Factor Load & Variance & Cronbach Alpha \\
\hline Working Conditions (Eigenvalue $=6.583$ ) & & 20.821 & 0.864 \\
\hline S2 & 0.788 & & \\
\hline S13 & 0.754 & & \\
\hline S12 & 0.742 & & \\
\hline S6 & 0.734 & & \\
\hline S1 & 0.683 & & \\
\hline S5 & 0.664 & & \\
\hline S4 & 0.574 & & \\
\hline S3 & 0.462 & & \\
\hline Social Conditions (Eigenvalue=3.045) & & 19.284 & 0.865 \\
\hline $\mathrm{S} 18$ & 0.798 & & \\
\hline S17 & 0.786 & & \\
\hline S19 & 0.746 & & \\
\hline S15 & 0.711 & & \\
\hline S16 & 0.685 & & \\
\hline $\mathrm{S} 20$ & 0.638 & & \\
\hline S14 & 0.552 & & \\
\hline Anxiety (Eigenvalue=1.790) & & 16.987 & 0.844 \\
\hline S9 & 0.854 & & \\
\hline S7 & 0.806 & & \\
\hline $\mathrm{S} 10$ & 0.793 & & \\
\hline S8 & 0.720 & & \\
\hline
\end{tabular}

carried out. The cmin/DF ratio of the scale is 2.879 according to the confirmatory factor analysis results; some data on compliance indices are as follows; GFI 0.942, NFI 0.943, IFI 0.962, TLI (NNFI) 0.953, CFI 0.962 and RMSEA 0.051. Indices show that the scale's congruence coefficient is acceptable or at the level of perfect congruence (18) reliability analyses of the data used after validity analyses have been done and, as shown in Table 1, the Cronbach alpha value of the scale is 0.838 . Also, the table shows the Cronbach alpha value of each dimension, which is more than 0.8 in each dimension as across the scale. This result shows that the scale is reliable (17).

\section{RESULTS}

According to the findings of the study, $31.7 \%$ of health care workers have been in contact with 19 cases of COVID-19; when the distribution of those who have been in contact according to their profession consists of $31.8 \%$ physicians, $42.5 \%$ nurses, $20.2 \%$ other health care workers and $5.5 \%$ administrative staff. These findings suggest that more groups of nurses came into contact with patients diagnosed with COVID-19. $27.3 \%$ of participants offered services to COVID-19 diagnosed patients. $30.3 \%$ of those providing services, were physicians, $38.3 \%$ were nurses, $25.9 \%$ were other health care workers, and 5.5\% were the administrative staff. According to the results of chi-square analysis, there is a significant relationship between the service providers with COVID-19 cases and those who came into contact with COVID-19 cases (Chi-square: 413,781; p: 0,000). Similarly, there is a relationship between health care workers' contact with COVID-19 cases (Chi-square: 9,092; p: 0,028) and their service delivery (Chi-square: 20,077; p: 0.000) and their profession.

In response to contact with cases of COVID-19 and providing services to them, health care workers were given a limited number of tests ( 35 people). 15 of the tested employees declared that COVID-19 test results were positive and 22 were negative. 4 of the positive findings have recovered, 5 have received services in the clinic and 6 have experienced uncertainty.

In the study, health workers were asked which countries were more successful in tackling COVID-19 and to rank the most successful countries in three categories. The most successful country at the first level according to the participants is China (31.2\%). China is followed by South Korea $(23.0 \%)$ and Germany (21.6\%). The second most successful countries are China (22.6\%), South Korea $(21.5 \%)$ and Germany (18.5\%); the third most successful countries are China (20.5\%), Germany (20.3\%) and Turkey. According to these findings, participants regard China, Germany, and South Korea as the three most successful countries. In contrast, respondents considered Italy the most unsuccessful country in the first place $(71.4 \%)$. Italy is followed by Turkey $(6.6 \%)$ and Iran $(6.3 \%)$. The three countries that failed in second place are Spain (32.7\%), Italy (25.9\%) and the United States (11.1\%). The third most unsuccessful countries are the United States (18.9\%), Spain (17.5\%) and Iran (16.3\%). According to these findings, Italy is one of the most successful countries in the fight against COVID-19. Other countries that have been seen as unsuccessful are Spain, Iran, and the United States.

As shown in Table 2, the participants' assessment of working conditions $(3.17 \pm 0.827)$ and their participation in social conditions $(3.24 \pm 0.739)$ were moderate, but their anxiety levels were quite high $(4.36 \pm 0.841)$. While there was moderate positive correlation relationships between reviews about the working conditions and social conditions of the participants $(r=0.551)$; there was a low and negative relationship between working conditions and anxiety levels $(r=-0.194)$ and social conditions ( $r=-0.105)$. 
Table 2. Correlation Analysis and Descriptive Statistics

\begin{tabular}{ccccc}
\hline & Mean & S.S. & $\mathbf{1}$ & $\mathbf{2}$ \\
\hline Working conditions (1) & 3,17 & 0,827 & 1 & \\
\hline Anxiety (2) & 4,36 & 0,841 &,$- 194^{\star *}$ & 1 \\
\hline Social conditions (3) & 3,24 & 0,739 &, $551^{\star \star}$ &,$- 105^{\star \star}$ \\
\hline
\end{tabular}

**. Correlation is significant at the 0.01 level (2-tailed).

\section{DISCUSSION}

In this study, which was carried out to determine how the health care workers in the COVID-19 outbreak assessed the working and social conditions and their anxiety levels, it was concluded that the health care workers were primarily at great risk. According to the results of the study, $31.7 \%$ of health care workers have had contact with cases of COVID-19, and $27.3 \%$ of participants provide services to patients diagnosed with COVID-19. Although there are no definitive data on COVID-19, studies of the SARS virus from the same family suggest that health care workers are at great risk. $30 \%$ of the 1755 SARS cases detected in Hong Kong, were health care workers (19). Similarly, in another study examining the SARS pandemic from February November 16, 2002, to February 9, 2003, 105 of the 305 cases were reported to be from health care workers (20). Another study suggests that SARS-CoV and MERS-CoV viruses spread between humans mainly through nosocomial transmission and that health care workers and relatives of patients are more affected by the infection (21).

$27.3 \%$ of the participants were individuals who provided services to patients with COVID-19 diagnosed. $30.3 \%$ of health care workers providing services were physicians, $38.3 \%$ were nurses, $25.9 \%$ were other health care workers and $5.5 \%$ were the administrative staff. There is also a relationship between the professions of health care workers who have been in contact with and providing services to cases of COVID-19. The distribution among health care workers who died in Singapore in the SARS outbreak also supports this situation. The probable SARS case identified in Singapore consisted of 49 nurses, 13 doctors and the remaining 22 other personnel of 84 health care workers (19). This suggests that the group of nurses who have to be with patients more are at greater risk.

One of the key results of the study is that a limited number of tests were conducted on health care workers who came into contact with cases of COVID-19 and provided services to them. According to the results of the study, only 35 (4.8\%) of the 736 health care workers who participated in the study underwent diagnostic testing. The results were positive in 15 (43\%) of the health care workers tested for diagnosis. Although the number of tests is very small, this result is important as it reveals the risk of COVID-19 transmission to health care workers. Furthermore, the Ministry of Health pronounced in a statement, as of 02.04.2020, 601 health care workers were diagnosed with COVID-19. Therefore, there are health care workers at the key point in the fight against the pandemic. For this reason, strict protection measures should be put in place in health institutions to protect health care workers. The introduction of strict control measures in studies on SARS has been very effective in preventing the subsequent spread of SARS. No further spread was observed from a patient after the application of strict infection control measures, including individual measures such as hand washing, N95 masks, working apron, and gloves before and after contact with the patient (22). A similar situation is also the case for the protection of health care workers. Furthermore, when taken into account that $47-57 \%$ of secondary cases exposed to SARS are health care workers, and only $14-19 \%$ are seen among patients and family members the importance of protecting health care workers becomes even more important (23).

Another important result of the study consists of findings on how health care workers evaluate public policies and what they think about Turkey's success. According to health care workers, the most successful country in the fight against COVID-19 is the People's Republic of China. This country is followed by Germany and South Korea. By contrast, the most unsuccessful country is decisively Italy, according to the participants. Italy is followed by Spain, the United States, and Iran. Although turnout is not very high, England and Turkey are among the countries that have failed to fight COVID-19.

According to the participants, working and social conditions are at a moderate level. However, anxiety levels are quite high. There is an inverse relationship between workers' anxiety levels and working conditions and social conditions, including higher working conditions. It is important that health care workers put the importance of improving their working environment to reduce anxiety levels in these results. In the SARS outbreak, $32-34 \%$ of health care workers were affected (23), it becomes even more important to ensure the appropriate conditions of working environments.

As a result, COVID-19 is a global phenomenon that poses a high level of anxiety over health care workers. To cope with this great pandemic, necessary measures must be taken to protect health care workers and their families and professional support must be provided to address their concerns. For this purpose, the necessary equipment can be provided in cooperation with health care workers.

\section{REFERENCES}

1. Wang D, Hu B, Hu C, Zhu F, Liu X, Zhang J, Wang B, Xiang, H. Clinical characteristics of 138 hospitalized patients with 2019 novel coronavirus-infected pneumonia in Wuhan, China. JAMA, 2020;323(11):1061-9. https://doi.org/10.1001/ jama.2020.1585 PMid:32031570

2. Li Q, Guan X, Wu P, Wang X, Zhou L, Tong Y, et al. Early transmission dynamics in wuhan, china, of novel coronavirus-infected pneumonia. The New England Journal of Medicine, 2020;382(13):1199-207. https://doi.org/10.1056/ NEJMoa2001316

3. Huang C, Wang Y, Li X, Ren L, Zhao J, Hu Y, et al. Clinical features of patients infected with 2019 novel coronavirus in Wuhan, China. Lancet, 2020;395(10223):497-506. https://doi.org/10.1016/S0140-6736(20)30183-5

4. WHO. Available at: https://www.who.int/docs/defaultsource/coronaviruse/situation-reports/20200402-sitrep72-covid-19.pdf?sfvrsn=3dd8971b_2 (Accessed: 3 April 2020).

5. Greenberg N, Docherty M, Gnanapragasam S, Wessely S. Managing mental health challenges faced by health care workers during the COVID-19 pandemic. BMJ, 2020:368. https://doi.org/10.1136/bmj.m1211 PMid:32217624

6. Lai J, Ma S, Wang Y, Cai Z, Hu J, Wei N, et al. factors associated with mental health outcomes among health care workers exposed to coronavirus disease 2019. JAMA, 2019; 3(3):e203976. https://doi.org/10.1001/jamannetwork open.2020.3976 PMid:32202646 PMCid:PMC7090843 
7. Driggin E, Madhavan MV, Bikdeli B, Chuich T, Laracy J, Bondi-Zoccai G, et al. Cardiovascular considerations for patients, health care workers, and health systems during the coronavirus disease 2019 (COVID-19). Journal of the American College of Cardiology, 2020; https://doi.org/ 10.1016/j.jacc.2020.03.031 PMCid:PMC7164881

8. The Ministry of Health. 2019 -COV disease health care workers guide (Science Board study). 2020. https://hsgm. saglik.gov.tr/depo/haberler/ncov/2019-nCov_Hastal_Salk _alanlar_Rehberi.pdf (Accessed: 2 April 2020).

9. Laia CC, Shih TP, Ko WC, Tang HJ, Hsueh, PR. Severe acute respiratory syndrome coronavirus 2 (SARS-CoV-2) and coronavirus disease-2019 (COVID-19): The epidemic and the challenges. International Journal of Antimicrobial Agents, 2020;55(3):105924. https://doi.org/10.1016/j.ijanti micag.2020.105924 PMid:32081636 PMCid:PMC7127800

10. Wang J, Zhou M, Liu, F. Reasons for health care workers becoming infected with novel coronavirus disease 2019 (COVID-19) in China. Journal of Hospital Infection, 2020. https://doi.org/10.1016/j.jhin.2020.03.002 PMCid:PMC7134479

11. Turkish Psychiatric Association. COVID-19 and stigma, Turkish Psychiatric Association, Mental Trauma, and Disaster Study Unit. 2020. Available at: https://www.psiki yatri.org.tr/uploadfiles/243202019327-damgalanmacovid. pdf (Accessed: 29 March 2020).

12. Baker MG, Peckham TK, Seixas NS. Estimating the burden of United States workers exposed to infection or disease: a key factor in containing the risk of COVID-19 infection. medRxiv, 2020. https://doi.org/10.1101/2020.03.02. 20030288

13. Erdem D, Atçı H, Akan B, Albayrak D, Gökçınar D, Göğüş N. The effect of intensive care work periods of anesthesiology and reanimation clinic assistants on, burnout, occupational performance, work-related tension and state-trait anxiety levels Sisli Etfal Hospital Medical Bulletin, 2010;44 (3):93-9.

\section{APPENDIX}

\section{Attitude and Opinion Scale of the Health Care Workers Against COVID-19 Pandemic}

1. I have enough personal protectors.

2. Required precautions were taken in the working environment.

3 I strictly follow the suggestions and rules.

4. My co-workers strictly follow the suggestions and rules.

5. Patients strictly follow the suggestions and rules.

6. Managers are sensitive to the problems that we convey about COVID-19.

7. I am concerned about COVID-19 contamination.

8. I am concerned about infecting my family and other people around me with COVID-19.

9. I am concerned about getting sick with COVID-19.

10. I am concerned about dying from COVID-19.

11 . I am concerned about causing to die a relative by infecting COVID-19.
14. Miguel - Tobal JJ, Gonzalez-Ordi H. The Role of emotions in cardiovascular disorders, In. Alexander-Stamatios G, Antoniou CL. (Eds.), Research companion to organizational health psychology, Cheltenham: Edward Elgar Publishing Limited. 2005:455-7.

15. Büyüköztürk Ş. Developing the Scale of Anxiety for Research. Educational Administration, 1997; 3(4):453-64.

16. Beaton R, Murphy P, Johnson C, Pike K, Corneil W. Coping responses and posttraumatic stress symposium in urban fire service personnel. J Trauma Stress, 1999;12(2):293-308. https://doi.org/10.1023/A:1024776509667 PMid:10378167

17. Coşkun R, Altunışık, R, Yildirim E. Research methods in Social Sciences (SPSS applied). 2017; Adapazarı: Sakarya Bookstore.

18. Karagoz Y. SPSS and AMOS Applied scientific research methods and publishing ethics, 2017; Ankara: Nobel Publication Distribution.

19. Eyigun CP. A new threat to health care workers: SARS. Journal of Hospital Infections, 2004;8(2):196-203.

20. Zhong NS, Zheng BS, Li YM, Poon LLM, Xie ZH, Chan KH, et al. Epidemiology and cause of severe acute respiratory syndrome (SARS) in Guangdong, People's Republic of China, in February 2003. Lancet, 2003;362(9393):1353-8. https://doi.org/10.1016/S0140-6736(03)14630-2

21. De Wit E, Doremalen N, Falzarano D, Munster VJ. SARS and MERS: recent insights into emerging coronaviruses. Nat Rev Microbiol, 2016;14(8):523-34. https://doi.org/10.1038/ nrmicro.2016.81 PMid:27344959 PMCid:PMC7097822

22. Riley P, Fraser C, Donnelly CA, Ghani AC, Abu-Raddad LJ, Hedley AJ, et al. Transmission dynamics of the etiological agent of SARS in Hong Kong: Impact of Public Health Interventions. Science, 2003;300(5627):1961-6. https://doi.org/10.1126 / science.1086478 PMid:12766206

23. Chowell G, Abdirizak F, Lee $P$, Lee J, Jung E, Nishiura $H$, Viboud C. Transmission characteristics of MERS and SARS in the healthcare setting: a comparative study. BMC Med., 2015;13(210):1-12. https://doi.org/10.1186/s12916-0150450-0 PMid:26336062 PMCid:PMC4558759

12. The institution that I work has the required equipment to respond for the epidemic.

13. The institution that I work maintains to intervene in the epidemic effectively.

14. The society follows the suggestions and rules in the fight against COVID-19.

15. Generally media and TVs broadcast with the rules in the publications about COVID-19 suitably.

16. Generally the posts about COVID-19 in social media are made in a way to strengthen the struggle.

17. In our country, the fight decisions regarding COVID-19 have been made correctly.

18. In our country, decisions to combat COVID-19 are effectively implemented.

19. Generally our country is more successful than Western countries in the fight against COVID-19.

20. The health system capacity of our country is at a level sufficient to deal with this epidemic. 